\title{
Thariqah Mubasyarah: Metode Pembelajaran Bahasa Arab pada Perguruan Tinggi
}

Thariqah Mubasyarah: Arabic Learning Method on Higher Education

\author{
Desky Halim Sudjani ${ }^{1 a}$, Gungun Gunadi ${ }^{1}$ \\ ${ }^{1}$ Program Studi Pendidikan Bahasa Arab, Fakultas Keguruan dan Ilmu Pendidikan \\ Universitas Djuanda Bogor, Jl. Tol Ciawi No.1 Kode Pos 35 Ciawi Bogor 16720 \\ ${ }^{a}$ Korespondensi: Desky Halim Sudjani, Email: desky.halim@unida.ac.id
}

\begin{abstract}
ABSTRAK
Pendidikan Bahasa Arab menjadi bagian dari program pengembangan sekolah-sekolah yang beratributkan agama Islam di Indonesia. Keberhasilan suatu kegiatan pembelajaran bergantung dari metode yang akan dipakai. Penelitian ini bertujuan untuk mengetahui sejauh mana thariqah mubasyarah dapat dipergunakan pada pembelajaran di perguruan tinggi. Penelitian ini dilakukan dengan studi pustaka dengan mengumpulkan sejumlah dokumen empiris. Hasil penelitian ini mengungkap bahwa thariqah mubasyarah merupakan metode pembelajaran bahasa Arab yang meniadakan penggunaan bahasa ibu. Thariqah mubasyarah diindikasikan dengan dominasi pembelajaran bahasa melalui tutur kata dengan penekanan pada penguasaan mufrodat dalam kehidupan sehari-hari. Juga, pembelajaran kaidah bahasa dilaksanakan dengan peragaan yang menuntut mahasiswa untuk menarik kesimpulannya masingmasing. Partisipasi aktif dosen dan mahasiswa ikut serta menjadi acuan keberhasilan proses pembelajaran. Penelitian berikutnya diharapkan meneliti implementasi thariqah mubasyarah pada mata kuliah tertentu.
\end{abstract}

Kata Kunci: thariqah mubasyarah, Perguruan Tinggi, Metode Pembelajaran

ABSTRACT

Arabic language education is part of the development program for schools that attribute the Islamic religion in Indonesia. The success of a learning activity depends on the method to be used. This study aims to determine the extent to which Tariqah Mubasyarah can be used in learning in tertiary institutions. This research was conducted with a literature study by collecting several empirical documents. The results of this study reveal that Tariqah Mubasyarah is an Arabic learning method that eliminates the use of the mother tongue. Tariqah Mubasyarah is indicated by the dominance of language learning through speech with an emphasis on mastering mufrodat in daily life. Also, language learning is carried out with demonstrations that require students to draw their conclusions. The active participation of lecturers and students takes part as a reference in the success of the learning process. The next research is expected to examine the implementation of Tariqah Mubasyarah in certain subjects.

Keywords: thariqah mubasyarah, higher education, learning method

\section{PENDAHULUAN}

Pendidikan Bahasa Arab menjadi bagian dari program pengembangan sekolah-sekolah yang beratributkan agama Islam di Indonesia (Madrasah Ibtidaiyah, Madrasah Tsanawiyah, Madrasah Aliyah, dan perguruan tinggi). Bahasa Arab masuk ke Indonesia seiring dengan penyebaran agama Islam (Ridlo, 2015). Bahasa Arab membentuk kebudayaan tertentu yang hidup pada sebuah lingkungan pendidikan tersebut. Tak berbeda dengan bahasa lainnya (Inggris, Korea, Mandarin, dan seterusnya), bahasa Arab dikategorikan bahasa asing di republik ini.

Kutip: Sudjani, D.H. \& Gunadi, G. (2020). Thariqah Mubasyarah: Metode Pembelajaran Bahasa Arab pada Perguruan Tinggi. Tatsqifiy: Jurnal Pendidikan Bahasa Arab, 1(1), 39-46 
Bahasa asing akan lebih sulit dipahami daripada bahasa ibu (Muradi, 2014). Selain kosakata yang jarang digunakan, struktur kata dan kalimat pun memerlukan waktu khusus untuk dipelajari. Oleh sebab itu pembelajaran bahasa asing dalam lembaga formal dan informal memerlukan metode pembelajaran yang tepat sesuai dengan tujuan umum pembelajaran bahasa itu sendiri (Nurgiyantoro, 2018).

Keberhasilan suatu kegiatan pembelajaran bergantung dari metode yang akan dipakai (Rifa’i, 2015). Metode pembelajaran berperan penting dalam keseluruhan proses pembelajaran. Peran suatu metode bersangkutan juga dengan mahasiswa yang menjadi objek pembelajaran. Tepat tidaknya guru dan/atau dosen dalam memilih metode pembelajaran adalah salah satu faktor keberhasilan seorang guru dan/atau dosen.

Peserta didik memerlukan metode pembelajaran yang menarik dan dapat memperjelas apa yang akan disampaikan oleh guru sehingga lebih cepat dipahami dan dimengerti mahasiswa. Kebanyakan sekolah masih menggunakan metode klasikal (berpusat pada guru) (Ulya, 2016).

Metode sebenarnya adalah seperangkat cara yang digunakan oleh seorang guru dan/atau dalam menyampaikan ilmu atau transfer ilmu kepada anak didiknya yang berlangsung dapam proses belajar dan mengajar atau proses pembelajaran (Nuha, 2016).

Metode pembelajaran sangatlah banyak dan beraneka ragam. Setiap metode mempunyai kelebihan dan kekurangan dibanding dengan metode lain. Dalam pembelajaran pendidik sering kali menggunakan metode secara bervariasi. Adapun metode yang digunakan itu berdiri sendiri, tergantung kepada pertimbangan yang didasarkan pada situasi pembelajaran yang relevan.

Salah satu metode yang dipergunakan pada perguruan tinggi adalah Thariqah Mubasyarah. Thariqah Mubasyarah semaksimal mungkin menghindarkan menerjemahkan arti kosa kata dari bahasa Arab ke dalam bahasa Indonesia. Thariqah mubasyarah pada perguruan tinggi umumnya dilakukan dengan berfokus pada intensitas penggunaan bahasa arab dari awal hingga akhir pembelajaran. Tentunya metode ini memerlukan interaksi sebagai bentuk konfirmasi atas penyampaian yang disajikan selama proses pembelajaran berlangsung. 
Pembelajaran perguruan tinggi khususnya mahasiswa program studi pendidikan bahasa Arab dituntut untuk menguasai bahasa Arab dengan cepat. Penguasaan bahasa Arab yang baik akan mendukung proses pembelajaran hingga menyelesaikan masa studi. Kenyataannya, ragam latar belakang mahasiswa juga turut memengaruhi metode pembelajaran yang dipergunakan pada tiap mata kuliah yang disajikan. Mahasiswa program studi pendidikan bahasa Arab Fakultas Keguruan dan Ilmu Pendidikan Universitas Djuanda didominasi latar pendidikan dari sekolah Madrasah Aliyah dan pondok pesantren. Asal sekolah telah memberikan pengenalan dan pemahaman bahasa Arab sehingga mahasiswa tidak terlalu kesulitan dengan thariqah mubasyarah.

Penelitian ini bertujuan untuk mengetahui sejauh mana thariqah mubasyarah dapat dipergunakan pada pembelajaran di perguruan tinggi.

\section{METODE}

Penelitian ini dilakukan dengan studi pustaka dengan mengumpulkan sejumlah dokumen empiris. Studi pustaka adalah kegiatan mendapatkan informasi dan data dari berbagai macam material yang ada di perpustakaan seperti dokumen, buku, catatan, majalah, kisah-kisah sejarah dan sebagainya (Mardalis, 1999) untuk mendapatkan sejumlah perspektif mengenai topik yang sedang diteliti (Sarwono, 2006).

Dokumen dikumpulkan dengan tahapan sebagai berikut: 1) membaca dan memelajari literatur, referensi atau bahan pustaka yang mempunyai korelasi dan dukungan terhadap topik Thariqah mubasyarah. 2) Mencatat halhal penting yang diharapkan dapat menemukan kajian-kajian yang relevan serta berkesinambungan dengan thariqah mubasyarah. 3) merekam dan memasukkan data yang diperoleh ke dalam instrumen analisis data. 4) melakukan generalisasi analisis data. 5) mendeskripsikan generalisasi sesuai dengan konteks perguruan tinggi

\section{HASIL DAN PEMBAHASAN}

Metode dapat dikatakan tepat guna apabila memperhatikan tujuan pembelajaran yang ditargetkan. Tujuan pembelajaran umumnya dibagi menjadi dua (umum dan khusus) (Khasanah, 2016).

Pembelajaran bahasa Arab secara umum bertujuan: 1) dapat memahami teks-teks agama (al-Qur'an dan Hadis) sebagai sumber hukum Islam dan ajaran; 2) memahami dan mengerti literatur-literatur asli yang ditulis dalam bahasa Arab; 3) pandai berbicara dan 
mengarang dalam bahasa Arab 4) dapat digunakan sebagai suplemen pendukung pembelajaran, dan; 5) membina ahli bahasa secara professional (Hizbullah \& Mardiah, 2015).

Secara khusus di Indoneisa, tujuan pembelajaran bahasa Arab menuntut mahasiswa 1) terampil dalam kemampuan mendengar dan berbicara (maharah istima'kalam) dengan isu yang komunikatif dan kontekstual dan, 2) terampil dalam kemampuan membaca dan menulis bahasa Arab (maharah qira'ah-kitabah), yaitu membaca teks isu sosial keagamaan, serta 3) menulis, yaitu menyimbolkan huruf/ katakata bahasa Arab dengan baik dan benar dalam konteks kebutuhan keseharian.

Thariqah Mubasyarah muncul setelah thariqah tarjamah. Kemunculan thariqah mubasyarah diindikasikan adanya pemikiran yang tidak mampu tersampaikan secara utuh jika menggunakan penerjemahan dalam memahami literatur asli berbahasa arab.

Al-Mubasyarah berasal dari kata بياثر - يباثر - (Baasyara-Yubasyiru-Mubasyaratan ) yang berarti langsung. Lebih lanjut, Thariqah Mubasyarah adalah metode pembelajaran bahasa Arab yang meniadakan penggunaan bahasa ibu. Penyampaian materi pelajaran dengan menggunakan Thariqah Mubasyarah semaksimal mungkin menghindari kegiatan menerjemahkan arti tiap kosakata dari bahasa Arab ke dalam bahasa Indonesia. Misalnya, apabila memperkenalkan isim (الاسم) maka langsung menunjukkan bendanya, misalnya (AlQalamu) maka langsung menunjukkan pena. Juga pada pembelajaran Fìil ( الفعل ) maka kata kerja tersebut diperagakan dengan gerakan (role-play) yang mengandung makna kata kerja tersebut, misalnya اكتب (Aktubu) maka diperagakan dengan tangan kiri seraya memegang buku, tangan kanan seraya memegang alat tulis, mata tertuju pada tangan kiri saat tangan kanan ikut digetarkan, dan sebagainya.

Pelaksanaan pembelajaran dengan menggunakan Thariqah Mubasyarah dihindarkan jauh-jauh mengartikan kosakata bahasa Arab, misalanya الكتب (Alkutubu) artinya buku, القلم (AlQalamu) artinya pena dan sebagainya. Akan tetapi seorang guru langsung menunjukkan bendanya disertai pertanyaan " ها ها (Maa hadzad) dan mahasiswa menjawab "ذلك (Dzaalika alkutubu) Kemudian dilanjutkan melakukan percakapan di antara sesama mahasiswa di dalam kelompok sampai semua mahasiswa benar-benar menguasai kosa kata yang sedang dipelajari tersebut. 
Upaya menjauhkan mahasiswa dari pemakaian bahasa yang sudah dikuasai sebelumnya baik itu bahasa ibu atau bahasa nasional bertujuan agar mahasiswa dapat lebih fokus dalam memelajari bahasa Arab sehingga hasilnya diharapkan lebih optimal. Mahasiswa juga tidak memerlukan tambahan kegiatan dengan menerjemahkan terlebih dahulu kosakata yang sedang dipelajari tersebut.

Thariqah Mubasyarah memiliki karakteristik sebagai berikut: 1) Target utama yakni penguasaan bahasa secara lisan, agar mahasiswa terbiasa berkomunikasi dengan bahasa secara spontan tanpa berorientasi pada terjemahannya. 2) Materi pelajaran berupa mufrodat (kosakata) yang ada di sekitar mahasiswa dan yang biasa dipraktekkan setiap hari. 3) kaidah bahasa diajarkan lewat contohcontoh dan pada akhirnya mahasiswa menyimpulkan sendiri. 4) Kosakata diajarkan melalui demonstrasi, peragaan benda (demonstrasi langsung) atau menggunakan media tiruan. 5) Kemampuan bicara dan menyimak selalu dilatihkan. 6) Dosen dan mahasiswa harus sama-sama aktif dalam proses kegiatan pembelajaran.

Thariqah mubasyarah sekurang-kurangnya memiliki prosedur dalam penyajian pembelajaran. Secara garis besar, penyajian metode tersebut adalah sebagai berikut: 1) Untuk menyebutkan kata yang bersifat isim, dosen mengucapkan satu kata sambil menunjukkan bendanya. 2) Untuk menyebutkan kata yang bersifat fiil, dosen mengucapkan satu kata sambil memeragakan dengan gerakan. 3) Latihan berikutnya berupa tanya jawab dengan kata tanya هل, ما, اين dan sebagainya. 4) Apabila mahasiswa telah menguasai materi yang disajikan, mahasiswa disuruh membuka buku teks dan guru memberikan contoh bacaan yang benar kemudian mahasiswa disuruh membaca bergantian. 5) Selanjutnya mahasiswa disuruh menjawab secara lisan pertanyaan yang ada di dalam buku, dilanjutkan dengan mengerjakan secara tertulis

Sebagai metode, perlu adanya pengukuran keberhasilan penerapan pada proses pembelajaran. Keberhasilan penerapan thariqah Mubasyarah tidak lepas dari faktorfaktor sebagai berikut antara lain: kecakapan dosen, materi atau bahan ajar, media pembelajaran, dan minat baca mahasiswa.

Dalam pelaksanaan pembelajaran bahasa Arab dengan menggunakan thariqah Mubasyarah, memerlukan dosen yang terampil dan aktif berbahasa Arab dan kreatif dalam mengajarkan bahasa Arab. Keterampilan tersebut sangat dibutuhkan 
karena posisi dosen merupakan salah satu faktor yang sangat menentukan keberhasilan tujuan pembelajaran yang akan dicapai. Dosen diharapkan dapat menyesuaikan pembelajaran dengan kondisi mahasiswa, tingkat pertumbuhan intelejensi, aspek sosial, ekonomi dan budaya (Rohman, 2014).

Di dalam memilih materi pembelajaran seorang guru harus benar-benar teliti. Buku harus sesuai dengan kondisi psikologis mahasiswa, sehingga sesuai dengan tingkat kemampuan mahasiswa. Demikian juga materi harus yang dipakai dikehidupan seharihari. Di sini akan menarik minat mahasiswa dan antusias dalam mempelajarinya. Tak kalah penting, metode pembelajaran diupayakan mengikuti asas pembelajaran secara bertahap, seperti dari yang mudah ke yang sulit, dari yang sederhana ke yang kompleks, dari yang jelas ke yang abstrak, dan dari yang hissi (indrawi) ke yang logika.

Sangat penting sekali menggunakan media dalam pembelajaran, melihat dalam materi ajar tidak semuanya benda dapat ditunjukkan langsung kepada mahasiswa. Bila benda-benda yang disebutkan di dalam materi ajar tidak ada di sekeliling mahasiswa, maka perlu adanya media berupa benda tiruan atau gambarnya. Dengan media tersebut akan membantu memudahkan belajar mahasiswa.
Minat ini merupakan faktor yang paling penting dalam pembelajaran. Bagaimanapun, mahasiswa merasa nyaman ketika proses pembelajaran dan mudah menangkap materi yang disampaikan yaitu apabila sudah adanya minat dalam mahasiswa tersebut untuk belajar bahasa Arab. Bagaimanapun, metode harus mampu mengakomodir semua perbedaan individual siswa di kelas, keragaman perilakunya, kecerdasan IQ-nya, dan kekuatan fisiknya. Terhadap perbedaan tersebut.

Thariqah mubasyarah sebagai sebuah metode memiliki kekuatan dan kelemahan. Kelebihan metode ini antara lain 1) Mahasiswa mampu menyimak dan berbicara menggunakan bahasa Arab dengan lancar. 2) Mahasiswa dapat menghafal kosa kata dengan baik. 3) Mahasiswa mengetahui banyak kosa kata dan pemakaiannya dalam kalimat. 4) Mahasiswa menjadi lebih memiliki keberanian berkomunikasi dalam bahasa Arab. 5) Mahasiswa mampu berkomunikasi secara sepontan dan secara lancar tanpa adanya hambatan harus berkonsentrasi pada penerjemahan. 6) Mahasiswa menguasai tata bahasa secara fungsional, tidak teoritis.

\section{Sebaliknya, thariqah Mubasyarah memiliki} kelemahan, antara lain: 1) mahasiswa lemah dalam interpretasi karena materi latihan ditekankan pada bahasa lisan; 2) metode ini 
memerlukan dosen yang aktif dan terampil berbahasa Arab dalam penyajian mata kuliah yang diampu; 3) pembelajaran tidak dapat dilaksanakan di dalam kelas besar; 4) kesulitan menjelaskan kata abstrak karena terhambat tidak diperbolehkannya menggunakan bahasa yang telah dikuasai sebelumnya; 5) kejenuhan dengan latihan menirukan dan menghafal kalimat-kalimat yang kadang-kadang dianggap kurang bermakna.

\section{KESIMPULAN}

Thariqah mubasyarah merupakan metode pembelajaran bahasa Arab yang meniadakan penggunaan bahasa ibu. Thariqah mubasyarah diindikasikan dengan dominasi pembelajaran bahasa melalui tutur kata dengan penekanan pada penguasaan mufrodat dalam kehidupan sehari-hari. Juga, pembelajaran kaidah bahasa dilaksanakan dengan peragaan yang menuntut mahasiswa untuk menarik kesimpulannya masing-masing. Partisipasi aktif dosen dan mahasiswa ikut serta menjadi acuan keberhasilan proses pembelajaran.

Penelitian ini dapat dikatakan sebagai awalan untuk memberikan masukan kepada penelitian selanjutnya. Penelitian berikutnya diharapkan meneliti implementasi thariqah mubasyarah pada mata kuliah tertentu.

\section{UCAPAN TERIMA KASIH}

Ucapan terima kasih disampaikan kepada para penelaah, antara lain: Dr. Muhammad Kamal Bin Abdul Hakim, M.A. (Universitas Negeri Jakarta) dan Dr. Akmal Walad Ahkas, M.A. (Universitas Islam Negeri Sumatera Utara) atas saran/masukan yang konstruktif pada artikel ini.

\section{DAFTAR PUSTAKA}

Hizbullah, N., \& Mardiah, Z. (2015). Masalah Pengajaran Bahasa Arab di Madrasah Aliyah di Jakarta. Jurnal Al Azhar Indonesia Seri Humaniora, 2(3), 189-198.

Khasanah, N. (2016). Pembelajaran Bahasa Arab Sebagai Bahasa Kedua (Urgensi Bahasa Arab Dan Pembelajarannya Di Indonesia). An-Nidzam: Jurnal Manajemen Pendidikan Dan Studi Islam, 3(2), 39-54.

https://doi.org/10.33507/annidzam.v3i2.16

Mardalis. (1999). Metode Penelitian Suatu Pendekatan Proposal. Jakarta: Bumi Aksara.

Muradi, A. (2014). Pendekatan Komunikatif dalam Pembelajaran Bahasa Arab. ARABIYAT: Jurnal Pendidikan Bahasa Arab Dan Kebahasaaraban, 1(1), 29-48.

Nuha, U. (2016). Ragam Metodologi \& Media Pembelajaran Bahasa Arab. Yogyakarta: Diva Press.

Nurgiyantoro, B. (2018). Penilaian Otentik dalam Pembelajaran Bahasa. Yogyakarta: UGM PRESS.

Ridlo, U. (2015). Bahasa Arab dalam Pusaran Arus Globalisasi: Antara 
46 Sudjani \& Gunadi

Thariqah Mubasyarah

Pesismisme dan Optimisme. Ihya Al-

https://doi.org/10.15408/a.v1i1.1131

'Arabiyah, 1(2), 210-226. Retrieved from

http://ejournalpba.org/index.php/ihya/a rticle/view/92

Rifa'i, A. (2015). Implementasi Thariqah Al Intiqaiyyah ( Metode Eklektik ) Pada Pembelajaran Bahasa Arab Di Mtsn Kediri 1. Realita, 13(2), 162-172.

Rohman, F. (2014). Strategi Pengelolaan Komponen Pembelajaran Bahasa Arab. ARABIYAT: Jurnal Pendidikan Bahasa Arab Dan Kebahasaaraban, 1(1), 63-78.

Sarwono, J. (2006). Metode Penelitian Kuantitatif dan Kualitatif. Yogyakarta: Graha Ilmu.

Ulya, N. M. (2016). Pengaruh Metode Pembelajaran dan Tipe Kepribadian Terhadap Hasil Belajar Bahasa Arab (Studi Eksperimen Pada MAN 1 Semarang). Nadwa: Jurnal Pendidikan Islam, 10(1), 1-25. https://doi.org/10.21580/nw.2016.10.1 .867 